ensaio

vol $8 \cdot \mathrm{n}^{\circ} 2 \cdot \operatorname{dez} .2006$

\title{
CONSTRUINDO VALORES ESTÉTICOS NAS AULAS DE CIÊNCIAS DESENVOLVIDAS EM AMBIENTES NATURAIS
}

\section{Constructing aesthetic values in science classes given in natural environment}

\author{
Tatiana Seniciato ${ }^{1}$ \\ Patrícia Gomes Pinheiro da Silva ${ }^{2}$ \\ Osmar Cavassan ${ }^{3}$
}

\section{RESUMO:}

O trabalho objetiva discutir as contribuições das aulas de ciências desenvolvidas nos ambientes naturais brasileiros para a construção de valores estéticos. A partir de duas experiências presentes em trabalhos de pesquisa em ensino de ciências, desenvolvidas com alunos de $6^{\underline{a}}$ séries do ensino fundamental público, pôde-se evidenciar em que medida os valores estéticos implícitos nessas práticas educativas emergem no comportamento dos alunos e em suas representações gráficas sobre o ambiente estudado. Os resultados encontrados nessas experiências sugerem que os alunos construíram valores estéticos a partir de aulas sobre conteúdos científicos, desenvolvidas em fragmentos de ecossistemas terrestres naturais brasileiros, sem que houvesse a intervenção do professor no sentido de propor reflexões quanto aos aspectos da vegetação ou à importância de sua preservação.

Palavras-chave: ensino de ciências; ambientes naturais brasileiros; valores estéticos.

\section{ABSTRACT:}

This paper discusses the contribution of science classes given in natural environment for building aesthetic values up. From two different experiences on research in science teaching, with $6^{\text {th }}$ grades of public elementary school, it have become evident the degree which such implicit aesthetic values, in these educational activities, emerge from students behavior and from their graphic representations about the studied environment. The obtained results suggest that students have developed aesthetic values on those classes, without theacher's interference in terms of proposing reflexion about the aspects of vegetation or the importance on preserving it.

Key-words: science teaching; brazilian natural environment; aesthetic values.

\footnotetext{
1 Pós-Graduação em Educação para a Ciência/UNESP/Bauru, Brasil (e-mail: tatianas@fc.unesp.br)

${ }^{2}$ Pós-Graduação em Educação para a Ciência/UNESP-Bauru, Brasil (e-mail: pgomes@fc.unesp.br)

${ }^{3}$ Departamento de Ciências Biológicas e Pós-Graduação em Educação para a Ciência/UNESP-Bauru, Brasil (e-mail: cavassan@fc.unesp.br)
} 


\section{INTRODUÇÃO}

Dentro das perspectivas atuais sobre quais deveriam ser os objetivos de uma educação de qualidade, há uma forte tendência em se afirmar que, ao formar o indivíduo, o processo educativo seja capaz de fornecer-lhe os instrumentos necessários não só para que atue em sua realidade, cuja garantia se daria pela apropriação de conhecimentos, mas, sobretudo, para que atue de forma consciente, participativa e ética e, para tanto, é imprescindível que se alie os valores ao corpo de conhecimentos.

Ao contrário da apropriação dos conhecimentos, que pressupõe uma certa formalização e sistematização na construção de conceitos, objeto de extensos estudos das ciências cognitivas (PIAGET, 1996, 2001; VIGOTSKI, 2001), os valores constituem, segundo autores como Morin (1990; 2000) e Gardner (1999), um domínio bem menos explícito da educação, porque implicam questões subjetivas que orientam nossa forma de agir e de pensar.

Disso decorre, por exemplo, que muitas vezes as práticas educativas restringemse ao domínio cognitivo e até mesmo a disciplinas específicas, sem preverem métodos que contemplem a formação de valores nos alunos, ainda que as propostas curriculares prevejam a dimensão filosófica na educação (BRASIL, 1998). No entanto, para Gardner (1999) a educação é um empreendimento muito mais amplo que envolve motivações, emoções, práticas e valores sociais e morais, de forma que, quando essas características do indivíduo não são incorporadas às práticas cotidianas, a educação é suscetível de ser ineficaz - ou de, o que é pior, produzir indivíduos que ferem as nossas noções de humanidade.

Os limites estabelecidos entre os valores são também menos nítidos que aqueles estabelecidos entre as disciplinas, mas estarão sempre relacionados à emissão dos juízos, às crenças, às opiniões e às escolhas a que estamos sujeitos na vida prática. Assim, podemos considerar os valores em sua dimensão moral, estética ou de reconhecimento da verdade.

Ainda segundo Gardner (1999) poucos negariam à escola o papel primordial na tarefa de inculcar conhecimentos e verdade. Entretanto, é muito menos certo se as escolas devem ser o principal comunicador de beleza e bondade. Nesse sentido, Piaget (2001) em sua teoria sobre o desenvolvimento da inteligência e da construção dos conhecimentos, já afirmava que a formação dos valores (ou dos critérios de moralidade) obedece, no sujeito, às mesmas relações lógicas próprias da formação dos conhecimentos, com a única diferença de que os valores são agrupados segundo uma escala e não em relações objetivas.

Para além das exposições teóricas, quais seriam então as práticas educativas que facilitariam a construção de valores morais e estéticos no âmbito da educação formal? Quais estratégias poderiam ser eficazes para o alcance desse objetivo? Para respondermos a essas perguntas, procuramos estabelecer dois limites: o primeiro será o de restringir o estudo dos valores à sua dimensão estética; o segundo será o estudo de uma estratégia específica de desenvolvimento de aulas de ciências e biologia em fragmentos dos ambientes naturais brasileiros.

A filosofia, ao longo da história, tem sido um contexto no qual tradicionalmente as questões estéticas são objeto de reflexão e de estudo. Na Grécia antiga as reflexões estéticas estavam centradas nas manifestações do belo natural e do belo artístico; já filósofos mais recentes, como Kant e Hegel, atribuiram os sentimentos estéticos a uma construção do sujeito, uma emissão de juízos do espírito humano às coisas (DUFRENNE, 1981).

Em termos educacionais, essa concepção de juízo estético se torna importante na medida em que é a apreciação ou a valorização que fazemos sobre algo, o julgamento que emitimos sobre determinada situação ou fenômeno. 
Além dessa concepção, ao discutirmos os valores estéticos no contexto deste trabalho, nos referimos também ao que Morin (2000) chama de emoção estética na educação. Seu pressuposto diz respeito, sobretudo, ao senso de deslumbramento, à qualidade poética dos quais deveriam estar revestidas as práticas educativas.

No caso das disciplinas científicas, desenvolver tais qualidades poéticas ou emoções estéticas pode ser particularmente difícil, visto que a ciência tende a se revestir de um caráter utilitarista e pragmático, e o desenvolvimento de aulas de campo em ambientes naturais tem sido apontado como uma estratégia eficiente para a superação dessa tendência (SENICIATO e CAVASSÃN, 2004; BENETTI, 2002; CHAPANI e CAVASSAN, 1997; CARVALHO, 1989).

Assim, serão relatadas duas experiências que discutem a contribuição das aulas de ciências desenvolvidas em ambientes naturais para a construção de valores estéticos. Como pontos comuns entre as experiências podemos considerar o fato de ambas serem oriundas de contextos de pesquisa em ensino de ciências, e de destacarem os valores estéticos implícitos na construção dos conhecimentos científicos em relação aos ecossistemas naturais.

\section{CONSTRUINDO VALORES ESTÉTICOS: O CERRADO E O JARDIM BOTÂNICO SÃO BONITOS}

Para que fossem avaliados e identificados os valores estéticos construídos nas aulas de ciências em ambientes naturais, foram desenvolvidas aulas com três turmas de $6^{a}$ séries do ensino fundamental da EMEF 'Cônego Aníbal Difrância', totalizando 97 alunos, em Bauru/SP, em agosto de 2001.

Tais aulas de campo foram desenvolvidas no Jardim Botânico Municipal de Bauru, onde foram abordados assuntos como biodiversidade dos ecossistemas nativos da região, ecossistemas terrestres brasileiros, componentes bióticos e abióticos de um ecossistema, formas de vida e relações entre os seres vivos.

O objetivo da aula de campo foi contextualizar os assuntos previamente estudados em sala de aula, sem que as questões referentes à preservação e à conservação da natureza fossem trazidas para o contexto da aula. As aulas foram conduzidas pela autora da pesquisa e contaram com a colaboração de duas monitoras, na época estagiárias do Herbário do Departamento de Biologia da UNESP/Bauru.

O Jardim Botânico Municipal de Bauru possui uma trilha ecológica que atravessa fragmentos de vegetação nativa de mata estacional semidecidual e de cerrado. Após a aula de campo, os alunos responderam questões em relação à estética e à preservação do ambiente, o que permitiu avaliar quais valores e referências em relação à natureza foram construídos.

Numa reflexão sobre o papel que o apelo estético desempenha na educação das crianças e adolescentes, Lanz (1990) expõe que o mundo fala à criança não pelo seu conteúdo conceitual, mas pelo seu aspecto e pela configuração dos seus fenômenos. Ela precisa identificar-se com o mundo, e para isto tanto melhor quanto mais belo o mundo se apresente, antes de tentar entendê-lo.

Da mesma forma, Alves (2000) salienta a importância dos valores estéticos na formação dos indivíduos:

Creio em valores estéticos. Acho que a vida e esta coisa indefinível que se chama felicidade se fazem não só com cifras da economia, mas freqüentemente contra elas. Há coisas que não podem ser trocadas por dinheiro: a beleza da Sete Quedas, o mistério de uma mata, e as memórias e fantasias de pios de corujas, regatos cristalinos, praias limpas, e bichos que nunca vimos mas que, sabemos, são nossos irmãos e partes deste mistério magnífico que é o nosso mundo, nosso lar, nosso corpo (ALVES, 2000, p.94). 
Partindo desse pressuposto, houve uma preocupação em relação a quais seriam as referências construídas pelos alunos, durante a aula de campo, no tocante à estética do ambiente natural.

Para isso, foi proposta a seguinte pergunta, a ser respondida pelos alunos por escrito: Você achou o aspecto do cerrado: bonito ( ) feio ( ). Por quê? - a qual pretendeu verificar como os alunos consideraram o aspecto do cerrado. A escolha do cerrado como representante do ambiente natural se deu de forma proposital. Durante a reunião com as professoras da escola, antes das definições sobre a pesquisa, foi mostrado à autora o livro didático de ciências adotado pela escola.

Numa breve análise do capítulo destinado ao estudo dos diferentes ecossistemas brasileiros, verificou-se que as referências apresentadas ao aspecto do cerrado eram negativas. A partir dessa constatação, foram analisados outros livros didáticos de ciências, adotados para as $6^{\sharp}$ séries do ensino fundamental da região de Bauru. Dessa análise, concluiu-se que a maioria das referências ao aspecto do cerrado, presentes nesses livros, era negativa (SENICIATO e CAVASSAN, 2002).

Segundo Bitencourt e Mendonça (2004), o aspecto e as características do cerrado têm servido, muitas vezes, de justificativa à intensa ocupação e à degradação observadas nas últimas décadas, por seu solo ser considerado 'pobre' e suas espécies vegetais de pouco valor econômico.

Desse modo, surgiram os seguintes questionamentos: Como os alunos considerariam o aspecto do cerrado durante a aula de campo nesse tipo de ecossistema? Será que os recursos didáticos tradicionais traduzem a realidade?

Dos alunos que participaram da aula de campo, 84 (ou 87,5\%) acharam o aspecto do cerrado bonito. Dentre as justificativas apresentadas para a indicação de que o cerrado é bonito, pode-se verificar aquelas que se referem estritamente à aparência externa do cerrado e ao reconhecimento de suas características marcantes (diferentes, na opinião dos alunos):

"Tem umas plantas bonitas e diferentes, os arbustos são interessantes e a coloração também é muito bonita."

"Porque tem árvores bonitas que não tem em outro lugar".

"Porque tem muitas coisas importantes para o nosso estudo e é bonito também. Eu adorei."

"As árvores do cerrado são baixas e tem flores e folhas adequadas ao ambiente."

"Porque os galhos das árvores são retorcidos e bem grossos."

"Algumas pessoas acham o cerrado feio, mas eu sei que é esse o aspecto e eu acho bonito."

"As plantas sempre nos fascinam, elas são ótimas."

"Porque como nós poderíamos achar feia a natureza?"

Ressalte-se, nesses resultados, que os alunos aceitaram de modo positivo as diferenças e características que observaram no cerrado, quando Ihes foi dada a oportunidade de julgarem por si mesmos sobre seu aspecto.

Mais que isso, de uma forma não intencional, os alunos justificaram a beleza do cerrado apontando também para algumas de suas características, o que pode contribuir para o melhor entendimento desse ecossistema. Uma justificativa, em particular, exemplifica esse fato: "O verde dele é muito bonito e as plantas deixam a luz entrar mais na mata.". As justificativas anteriores também destacaram o verde do cerrado; porém nessa última, o aluno reconhece que a luz, no ambiente do cerrado, é mais intensa que no ambiente de mata, pelo fato de as plantas não formarem um dossel fechado. Na verdade, o destaque do verde é maior justamente pelo aumento na intensidade de luz refletida, captada pela retina dos alunos.

O posicionamento 'filosófico' dos alunos em relação à natureza revela o surgimento de emoções positivas durante a aula de campo. Podemos caracterizar essas emoções como sendo estéticas, assim denominadas por Morin (2000), pois nelas há um evidente senso de deslumbramento com os elementos naturais. Como bem aponta Damásio (2001), se o ensino preocupar-se em proporcionar emoções 
positivas nos alunos, irá formar adultos mais aptos a tomarem decisões sensatas e também a respeitarem o valor da vida.

Em nenhum momento durante a aula de campo, as monitoras conclamaram os alunos a protegerem a natureza, a militarem em seu favor, a assumirem posturas políticas ou sociais. O objetivo da aula foi estritamente o de contextualizar os conteúdos de ecologia estudados em sala de aula. Contudo, as emoções desencadeadas pela beleza da natureza e a sensação de bem-estar por ela proporcionada parecem ter favorecido a seguinte justificativa, em relação ao cerrado: "É muito gostoso, é bonito demais. Quando eu crescer eu quero estudar as plantas e também não vou deixar ninguém destruir a natureza".

Porém, nem todos acharam o cerrado bonito. Dos alunos que participaram da aula de campo, 13 (ou 12,4\%) consideraram o aspecto do cerrado feio. Das justificativas apresentadas, todas se referiram ao aspecto seco do cerrado: "Pois ele está seco.", "Porque ele é uma planta seca.", "Está tudo seco, pouco bonito."

De fato, a época em que foram desenvolvidas as aulas correspondeu ao final do inverno (13 a 15 de agosto de 2001). Talvez, se as aulas tivessem sido desenvolvidas a partir de setembro, os resultados poderiam diferir dos aqui apresentados.

Interessante notar que nenhum aluno justificou o aspecto feio, atribuído ao cerrado, referindo-se às árvores retorcidas, baixas ou cascudas; pelo contrário, essas foram características apontadas para justificar sua beleza.

Embora o objetivo da aula de campo no Jardim Botânico tenha sido o de aprendizagem dos conteúdos referentes à ecologia e às características dos ecossistemas terrestres naturais da região de Bauru/SP, foi proposta uma questão, também respondida por escrito, em relação à preservação do ambiente: "Para você, a vegetação do Jardim Botânico deve: () ser destruída ( ) ser preservada ( ) eu não me importo se ela será destruída ou preservada. Por quê?"

Essa questão procurou avaliar se as sensações e a construção de conhecimentos envolvidos durante a aula de campo contribuiriam para que os alunos assumissem posturas em relação ao ambiente, sem que as pessoas que conduziam a aula sugerissem alguma reflexão nesse sentido.

Todos os alunos que participaram da aula de campo apontaram para a preservação da vegetação do Jardim Botânico. As justificativas apresentadas, porém, referiram-se a aspectos diversos, com forte presença de juízos estéticos. Houve aquelas que reconheceram a importância do ambiente para a aprendizagem dos assuntos apresentados:

"Por que é um lugar onde se aprende muitas coisas e é muito gostoso ficar lá dentro."

"Por que se destruirmos a vegetação não tem mais o que aprender."

"É muito importante para que as pessoas conheçam coisas novas como eu."

"Por que se ele continuar, podemos aprender mais."

Parece estar implícito nas justificativas dos alunos que o ambiente motivou a aprendizagem. Esse pode ser um dado importante no planejamento das aulas de ciências, de modo a torná-las mais prazerosas e eficientes.

A aula de campo também favoreceu uma visão complexa da existência das muitas formas de vida na natureza e sua interdependência. Os alunos reconhecem a importância da vegetação para os animais, para a manutenção dos fatores abióticos e para si mesmos, porém sem uma postura antropocêntrica ou utilitarista, mas sim de integração ao ambiente e de emoções estéticas positivas:

"Porque no Jardim Botânico não é só para ver, tem animais que moram lá."

"Para que possa manter sempre limpo e fresco, para não destruir a natureza."

"É o habitat de muitas espécies de vegetais e animais e sem ela, perdemos o que temos de melhor."

"Porque precisamos das árvores e a sombra deixa os lugares mais bonitos." 


\section{ensaio}

vol $8 \cdot \mathrm{n}^{\circ} 2 \cdot \operatorname{dez} .2006$

Um aspecto importante revelado pela aula de campo é o fato de os alunos recorrerem aos sentidos para o reconhecimento do ambiente (os sons, os cheiros, a beleza, a temperatura etc). No Jardim Botânico, a natureza revelou-se concretamente aos alunos:

"Para continuar sendo o que é, bonito, limpo, confortável e além de tudo perfumado."

"Porque é o lugar mais limpo, mais fresco e mais verde que eu já vi."

"Para continuar lindo e confortável do jeito que está."

"Para a gente continuar sentir o cheiro da natureza."

"Porque é um lugar que a gente pode escutar os barulhos dos ventos e dos pássaros. É um lugar gostoso."

Considerando-se que todos os alunos envolvidos na pesquisa eram residentes da zona urbana, infere-se que estivessem acostumados às paisagens e à realidade da cidade. Assim, parece lógico que muitos justificaram a manutenção da vegetação do Jardim Botânico por reconhecerem a importância das áreas de proteção para o equilíbrio dos sistemas e para o bem-estar das populações. Do mesmo modo, muitos fazem comparações com a zona urbana e ressaltam o prazer que sentiram em contato com a natureza:

"É muito difícil achar uma vegetação tão bem cuidada como lá, então vamos preservar."

"Porque mostra um pouco da natureza que existia em nossa cidade."

"Para que Bauru tenha mais lugares agradáveis."

"Porque é uma parte de Bauru pura e limpa que ainda resta no meio de carros e prédios."

Saliente-se que as sensações expressas nas justificativas dos alunos não poderiam surgir a partir de uma aula teórica tradicional, principalmente aquelas referentes ao tato (sensação de frescor), ao olfato (cheiros) e à audição (barulhos).

A experiência evidenciou a importância de se fornecerem oportunidades nas aulas de ciências para que os alunos construam seus próprios valores estéticos em relação à natureza, a partir do estabelecimento de relações entre as diferentes realidades e da apresentação da complexidade dos fenômenos naturais. Em outras palavras, para que a emissão de juízos sobre o que é belo e agradável seja socialmente possibilitada, mas pessoalmente construída.

\section{A EXPOSIÇÃO DE DIFERENTES VALORES ESTÉTICOS A PARTIR DE REPRESENTAÇÕES GRÁFICAS DO AMBIENTE NATURAL}

Preocupações referentes às imagens na educação em ciências vêm crescendo no âmbito nacional através de pesquisas sob várias perspectivas. Alves (2001) enfatiza a relevância desses estudos ao destacar a falta de clareza da importância da imagem para a compreensão e o conhecimento da realidade, que por muito tempo se sustentou em uma sociedade formada em torno do sentido da visão e da perspectiva. Uma mudança exigiria a indicação da possibilidade de superação da própria lógica dominante.

Um consenso existente nesse contexto refere-se à presença crescente da imagem e à quase impossibilidade de se falar, estudar ou ler algo sem usá-las. Desse modo, como coloca Monteiro (2001, p. 28), devemos "aprender a ver":

Ver não é somente olhar. O ver necessita estar e não apenas passar pelos espaços. [...] Ver é observar a realidade que se apresenta de forma complexa e inteira diante do seu olhar. Ver não é se colocar como espectador de um mundo ilusório criado por outros olhares.

Martins et al. (2003), em um trabalho sobre leitura que os alunos fazem das imagens revela, ainda, a existência de uma diversidade de formas de engajamento tanto nos campos afetivo e cognitivo quanto no campo estético. 
Considerando-se especificamente o campo estético, foi desenvolvido um trabalho junto a duas turmas de alunos de $6^{\underline{a}}$ série ( $6^{\underline{a}} \mathrm{C}-14$ alunos e $6^{\mathrm{a}} \mathrm{D}-25$ alunos) da escola estadual de ensino fundamental e médio "Rubens Pietraróia" de Lençóis Paulista/SP, envolvendo a utilização de imagens e a importância das aulas práticas de campo para o estudo dos vegetais.

Um dos objetivos desse trabalho foi analisar, nas representações gráficas dos alunos referentes à "floresta", os valores estéticos envolvidos, considerando-se diferentes procedimentos: 6a D - desenhos elaborados após aula teórica sobre os vegetais, baseada nas ilustrações do livro didático adotado pelos professores, e após aula prática de campo desenvolvida em um fragmento de mata estacional semidecidual e mata paludosa pertencente à empresa Duratex/Agudos; 6a $\mathrm{C}$ - desenhos elaborados após aula prática de campo no mesmo fragmento de floresta nativa e após aula teórica sobre os vegetais, utilizando as ilustrações do livro didático.

É importante considerar que foi feita, previamente, uma análise das ilustrações do livro didático que os professores adotavam na escola, detectando-se a presença de espécies exóticas como exemplos de determinados grupos vegetais e a quase ausência de legendas indicando nomes, escalas e proporções das espécies apresentadas.

Analisando-se os desenhos elaborados pelos alunos da $6^{\underline{a}} \mathrm{D}$, pode-se notar uma considerável diferença nas representações feitas após cada etapa.

Como mostram as figuras 1 e 2, após aula teórica baseada na observação e no reconhecimento de cada vegetal estudado a partir das ilustrações do livro didático e, considerando-se também as concepções e experiências prévias de cada aluno, percebese claramente a interferência da mídia, do livro didático adotado e dos mais variados recursos disponíveis para elaboração de um conceito ou imagem da "floresta", principalmente devido às limitações que tais recursos proporcionam.

Outro fator relevante é a interferência do ambiente, muitas vezes exótico, no qual a espécie vegetal está inserida, favorecendo a descaracterização da vegetação nativa, fato já ressaltado em Pinheiro da Silva e Cavassan (2003).

Nesse contexto, as noções de diversidade e de complexidade são perdidas ou mesmo não construídas, como demonstram as representações.

A homogeneidade e a presença de elementos de ambientes característicos de outros países são encontradas compondo a floresta, a qual também é apresentada por meio de uma organização dos elementos (sol entre as montanhas, gramíneas sob as árvores espaçadas e de formas idênticas, um riozinho passando, etc), de modo a criar estereótipos. Tais estereótipos podem influenciar na formação de valores estéticos desses alunos na medida em que sugerem a relação direta entre "beleza" e "organização".

De acordo com Pegoraro (1998), a profusão de informações envolvendo flora, fauna e paisagens exóticas, incluídas em contextos idealizados e pouco realistas, contribuem com uma visão de natureza que pode dificultar a compreensão da dinâmica dos ambientes naturais, regionais e locais, bem como da rica diversidade biótica que os compõe. Ainda segundo o mesmo autor, tais abordagens reforçam um senso comum bastante empobrecido quanto às espécies nativas e aos ambientes naturais nos quais se encontram. Nesse sentido, iniciativas que promovam o contato e a aproximação dos ecossistemas nativos e que, simultaneamente, envolvam as dimensões cognitiva e afetiva, são imprescindíveis. 


\section{ensaio}

vol $8 \cdot n^{\circ} 2 \cdot$ dez. 2006

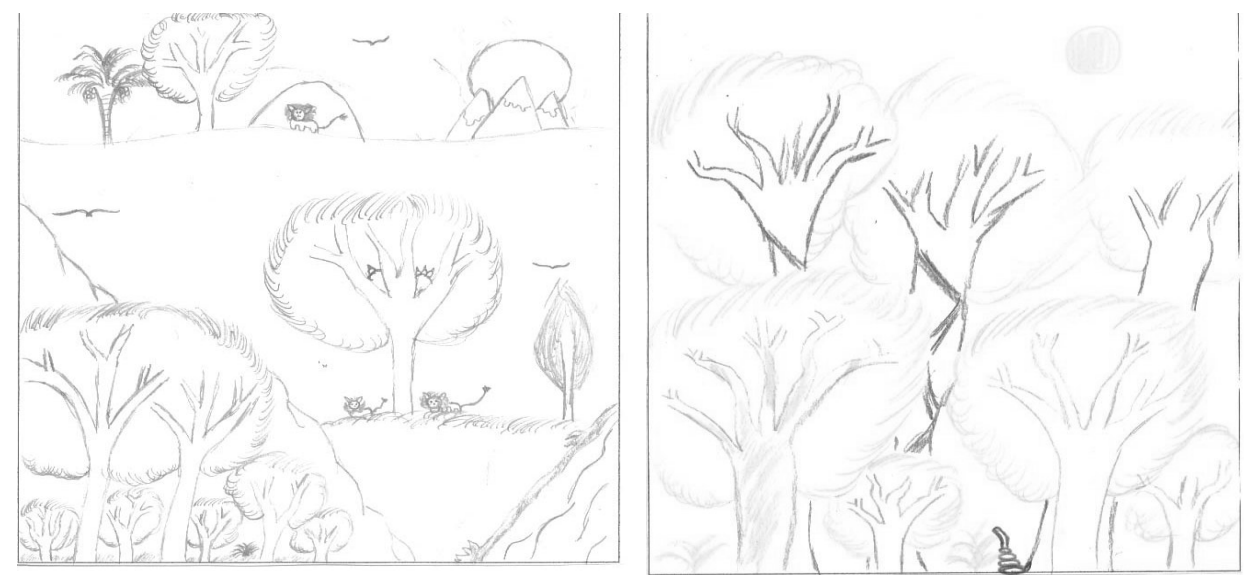

Figura 1 - Representações da floresta feitas por um mesmo aluno da $6^{\underline{a}} \mathrm{D}$ após aula teórica e aula prática de campo, respectivamente.

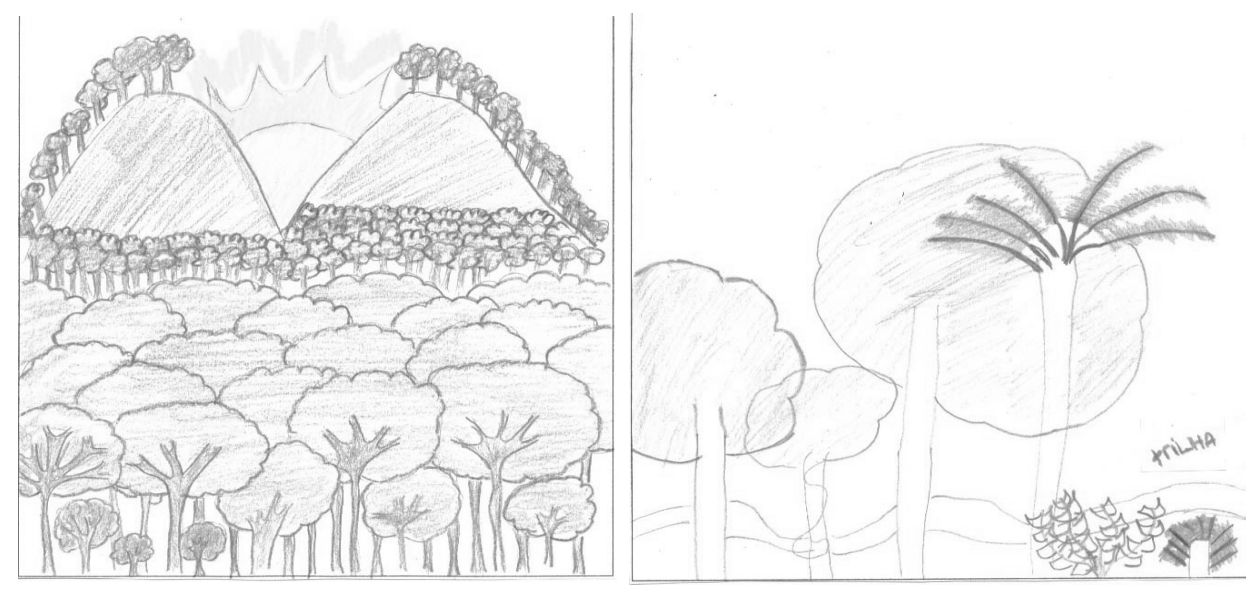

Figura 2 - Representações da floresta feitas por um mesmo aluno da $6^{\underline{a}} \mathrm{D}$ após aula teórica e aula prática de campo, respectivamente.

Após aula prática de campo, notou-se maior dificuldade de representação de floresta. No entanto, houve também maior preocupação com os elementos a serem representados, não se restringindo tanto aos aspectos visuais e à organização desses elementos, como o observado anteriormente.

$\mathrm{O}$ contato direto do aluno com os vegetais em seu ambiente natural permite que ele esteja mais atento aos fatores que interferem naquele local e às relações existentes entre as diferentes espécies, levando-o a ter consciência de sua diversidade e sua complexidade (PINHEIRO da SILVA e CAVASSAN, 2002 e PINHEIRO da SILVA, 2004). Nesses desenhos, a "bagunça" ou a "desordem" não mais se relacionam à "feiúra", à "aversão" e, muitas vezes, ao "medo", mas sim à "beleza", à "harmonia" e ao "fascínio", demonstrando os valores estéticos envolvidos.

Como colocam Chapani e Cavassan (1997), é importante que o professor desenvolva atividades que possam dar ao aluno uma visão mais clara das relações 


\section{ensaio}

$\operatorname{vol} 8 \cdot \mathrm{n}^{\circ} 2 \cdot$ dez. 2006

que ocorrem no ambiente, estimule a reflexão a respeito dessas relações e, especialmente, leve a criança a amar a natureza.

Analisando-se a seqüência inversa de atividades $\left(6^{\underline{a}} \mathrm{C}\right)$, representações com características muito semelhantes àquelas descritas acima, após o contato com o ambiente natural, foram observadas. Poucos elementos representados, maior diversidade de espécies e dificuldades de representação da floresta, uma vez constatada a complexidade desse ambiente, são encontrados nas figuras 3 e 4 .
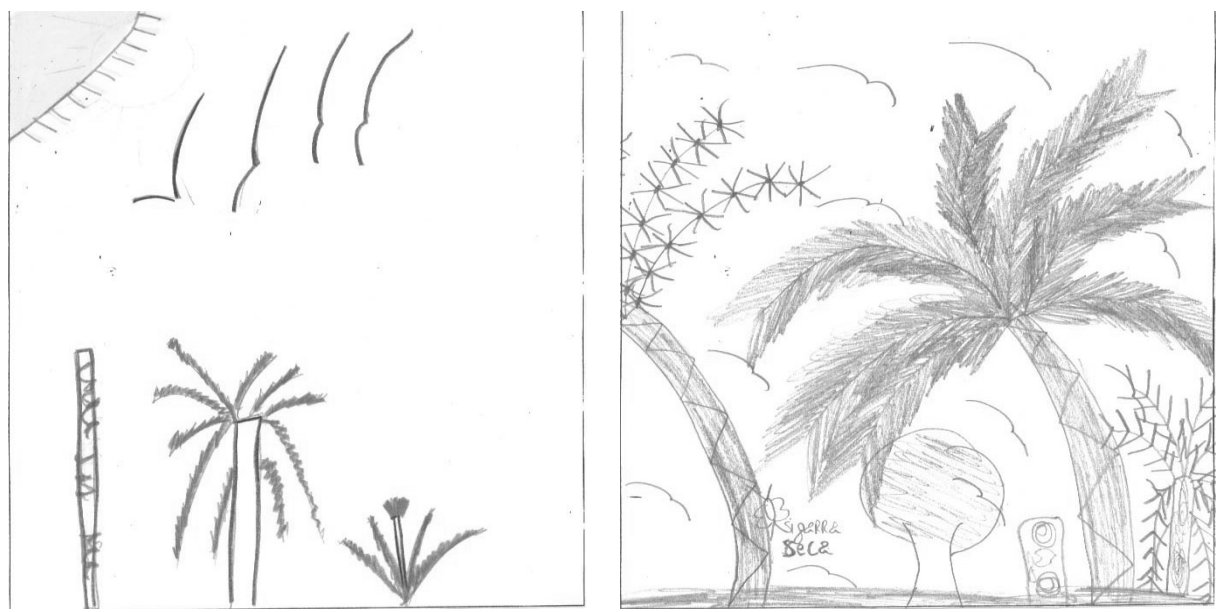

Figura 3 - Representações da floresta feitas por um mesmo aluno da 6a C após aula prática de campo e aula teórica, respectivamente.
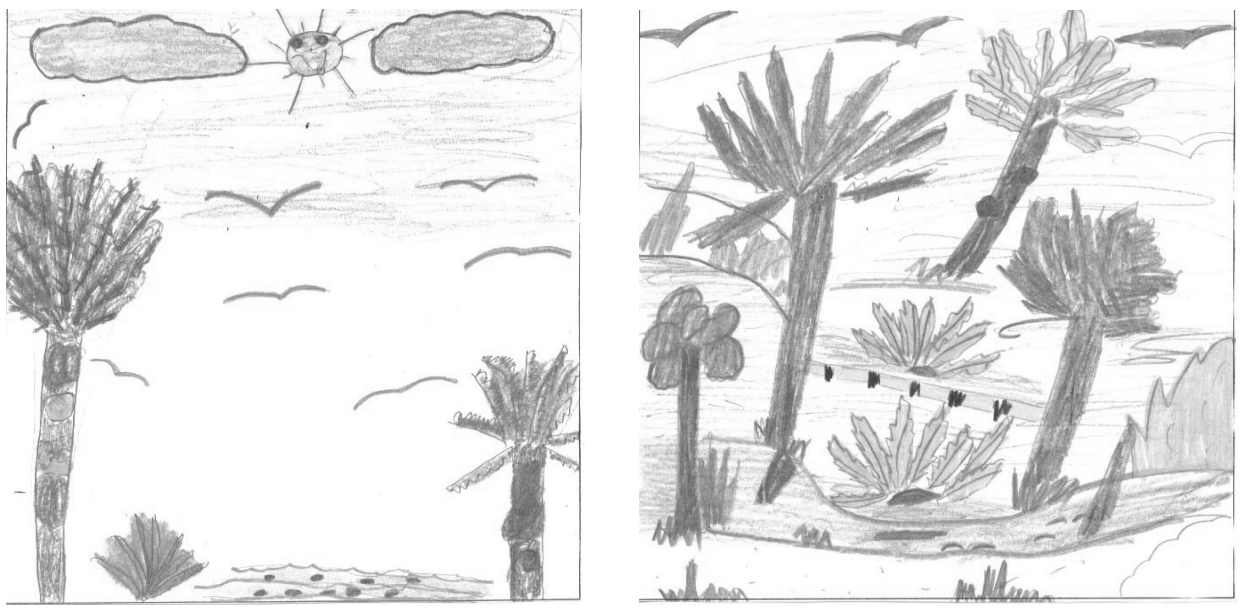

Figura 4 - Representações da floresta feitas por um mesmo aluno da 6a $\mathrm{C}$ após aula prática de campo e aula teórica, respectivamente. 
A permanência dessas características e dos valores estéticos envolvidos e representados nos desenhos finais dos alunos da $6^{\underline{a}} \mathrm{C}$ permite dizer que 0 desenvolvimento de aulas teóricas baseadas no uso de ilustrações botânicas presentes nos livros didáticos após aulas práticas de campo é possível, desde que bem planejadas e com objetivos claros, revelando-se até mesmo mais eficientes. Nesse caso, muitas críticas às ilustrações do livro didático foram feitas pelos alunos, sugerindo a inclusão de espécies nativas como exemplos do conteúdo estudado.

Segundo Martins et al. (2003), as imagens não possuem significado imediato e transparente e sua leitura é uma atividade complexa, sendo necessário partir da realidade para sua compreensão.

Em relação à importância do uso dos desenhos, Dove et al. (1999, p. 496) colocam: Os desenhos das crianças podem revelar concepções distorcidas da realidade, as quais, não sendo detectadas, podem atuar como barreiras para uma aprendizagem significativa.

Assim, conhecer a maneira como as pessoas percebem o ambiente, a forma de interação com ele e quais valores aplicam nessa interação, pode auxiliar na compreensão da sua visão de mundo e da sua capacidade de ação efetiva e responsável nas questões que envolvem a preservação ambiental (MOREIRA e SOARES, 2002).

\section{CONSIDERAÇÕES FINAIS}

A proposta deste trabalho foi discutir o quanto um ambiente de ensino permite a construção de valores estéticos nos processos de ensino e de aprendizagem, de modo particular, como atividades de campo em ambientes abrigando fragmentos de ecossistemas terrestres naturais podem contribuir com esse propósito.

Alves (2000) afirma que se os alunos não se apaixonarem pela ciência, todo o esforço empenhado no ensino das disciplinas científicas terá sido em vão. Pior que a inocuidade do ensino, é um ensino que causa repulsa pelo conhecimento. Segundo Tierdermann (1998), se o aluno não perceber a beleza do que está sendo ensinado, é natural que passe a desprezar ou mesmo odiar a matéria.

Do mesmo modo, se o aluno não desenvolver uma relação harmoniosa com o assunto adquirirá, como profissional ou cidadão, relações de indiferença ou hostilidade em relação a ele. As referências positivas, no contexto de uma aula tradicional, podem ser advindas de um ensino reflexivo, da ideologia implícita ou explícita na prática pedagógica do professor. Mas, como esse professor pode pretender tais referências se ele mesmo não as tem?

Em cursos de Licenciatura em Ciências Biológicas, o conteúdo programático das disciplinas de Ecologia inclui tópicos de Ecologia de Comunidades Vegetais e Formações Vegetais Terrestres com ênfase às que ocorrem no Brasil.

O estudo teórico desse assunto necessita de grande capacidade de abstração dos licenciandos. O uso de imagens projetadas, textos de livros e de revistas não se revelam suficientes para favorecer o estabelecimento de referências positivas em relação aos ambientes naturais. Assim, o futuro professor teria dificuldades ao ministrar aulas sobre esse assunto, de demonstrar e desejar que seus alunos também desenvolvam referências positivas a respeito de nossos ecossistemas terrestres naturais.

A inserção de atividades práticas de campo em ambientes naturais durante viagens de estudos programadas fora do período de aulas pode ser um contexto de construção de conhecimento, de aprendizagem, de curiosidade, de motivação e de interesse pela aquisição de novos saberes pelos licenciandos, capacitando-os, portanto, a reproduzir estratégias equivalentes com resultados mais significativos no processo aprendizagem. 


\section{ensaio}

vol $8 \cdot \mathrm{n}^{\circ} 2 \cdot \operatorname{dez} .2006$

Da mesma forma, as experiências relatadas demonstraram, por meio das manifestações espontâneas dos alunos, maior motivação e interesse em estudar aqueles conteúdos. Pôde-se verificar também a formação de valores estéticos em relação aos ambientes nos quais as aulas foram desenvolvidas, além de uma maior preocupação com o estado de preservação e com o destino dos ambientes naturais visitados.

$\mathrm{Na}$ avaliação de imagens, percebeu-se a forte influência da educação pretérita não-escolar nas representações dos alunos como, por exemplo, a inclusão de elementos naturais de outros países. Após a aula de campo, as representações antes pobres em detalhes e com contornos definidos, tornaram-se mais complexas, com maior riqueza de detalhes de formas e de cores, reflexo das altas diversidade e complexidade dos ecossistemas visitados, sugerindo a apropriação de uma estética mais próxima da realidade brasileira.

Os resultados encontrados nessas experiências sugerem que os alunos construíram valores estéticos a partir de aulas sobre conteúdos científicos desenvolvidas em fragmentos de ecossistemas terrestres naturais brasileiros, sem que houvesse a intervenção de pessoas responsáveis pela condução da aula no sentido de proporem reflexões quanto aos aspectos da vegetação ou à importância de sua preservação.

De acordo com Gardner (1999), é importante que cada cultura identifique as verdades, as belezas e virtudes a que dá valor, e que dedique, portanto, recursos para inculcar seu entendimento nos jovens estudantes, de modo que os permita sintetizar suas próprias virtudes. 


\section{ensaio}

vol $8 \cdot \mathrm{n}^{\circ} 2 \cdot$ dez. 2006

\section{REFERÊNCIAS BIBLIOGRÁFICAS}

ALVES, N. Imagens das escolas. In: ALVES, N.; SGARBI, P. (orgs.). Espaços e imagens na escola. Rio de Janeiro: DP\&A, 2001. p. 7-17.

ALVES, R. Estórias para quem gosta de ensinar. 168 p. 2. ed. Campinas: Papirus. 2000.

BENETTI, B. A temática ambiental e os procedimentos didáticos: perspectivas de professores de ciências. In: VIII ENCONTRO "PERSPECTIVAS DO ENSINO DE BIOLOGIA". 6., 2002, São Paulo. Anais...São Paulo: FEUSP, 2002. 1 CD-ROM.

BITENCOURT, M. D.; MENDONÇA, R. R. Viabilidade de conservação dos remanescentes de cerrado no Estado de São Paulo. São Paulo: Annablume; Fapesp, 2004. 169p.

BRASIL. Secretaria de Educação Fundamental. Parâmetros curriculares nacionais: ciências naturais. Brasília: MEC/SEF, 1998. 138p. (terceiro e quarto ciclos do ensino fundamental).

CARVALHO, L.M. A temática ambiental e a escola do $1^{\circ}$ grau. 1989. 286 p. Tese (Doutorado em Educação) - Faculdade de Educação, Universidade de São Paulo, São Paulo, 1989.

CHAPANI, D.T., CAVASSAN, O. O estudo do meio como estratégia para o ensino de Ciências e educação ambiental. Mimesis. Bauru, v. 18, n.1, p.19-39, 1997.

DAMÁSIO. A.R. O erro de Descartes. São Paulo: Companhia das Letras. 2001.330p.

DOVE, F. E.; EVERETT, L. A.; PREECE, P. F. W. Exploring a hydrological concept through children's drawings. International Journal of Science Education, v. 21, n. 5, p. 485-497, 1999.

DUFRENNE, M. Estética e Filosofia. 2ª ed. São Paulo: Perspectiva. 1981.

GARDNER, H. O verdadeiro, o belo e o bom: os princípios básicos para uma nova educação. Rio de Janeiro: Objetiva. 1999. 361p.

LANZ, R. A pedagogia Waldorf. 5. ed. São Paulo: Antroposófica. 1990. 179 p.

MARTINS, I. et al. Lendo imagens no livro didático de ciências. In: SIMPÓSIO NACIONAL DE ENSINO DE FÍSICA, 15., 2003, Curitiba. Anais... Curitiba, 2003. 1 CD-ROM.

MONTEIRO, S. C. F. Aprendendo a ver: as escolas da/na escola. In: ALVES, N.; SGARBI, P. (orgs.). Espaços e imagens na escola. Rio de Janeiro: DP\&A, 2001. p. 27-39.

MOREIRA, A. L. O. R.; SOARES, J. J. Percepção de floresta - uma pesquisa entre visitantes de 7 a 12 anos do Parque do Ingá, Maringá-PR. In: ENCONTRO PERSPECTIVAS DO ENSINO DE BIOLOGIA, 8., 2002, São Paulo. Anais...São Paulo: FEUSP, 2002. 1 CDROM.

MORIN, E. Ciência com consciência. Portugal: Europa/América. 1990. 261p.

MORIN, E. A cabeça bem feita: repensar a reforma, reformar o pensamento. 2. ed. Rio de Janeiro: Bertrand Brasil, 2000. 128p. 


\section{ensaio}

vol $8 \cdot \mathrm{n}^{\circ} 2 \cdot \operatorname{dez} .2006$

PEGORARO, J. L. Educação ambiental: a temática da flora, da fauna e dos ambientes naturais (expressões da biodiversidade) a partir da educação formal. 1998. 203 p. Dissertação (Mestrado em Ciências)- Escola Superior de Agricultura "Luiz de Queiroz" da Universidade de São Paulo, Piracicaba, 1998.

PIAGET, J. Biologia e conhecimento - ensaio sobre as relações entre as regulações orgânicas e os processos cognoscitivos. 3ª ed. Petrópolis/RJ: Vozes. 1996. 423 p.

PIAGET, J. Seis estudos de psicologia. 24. ed. Rio de Janeiro: Forense Universitária. 2001. 136p.

PINHEIRO da SILVA, P. G.; CAVASSAN, O. A interferência da educação informal nos programas de educação ambiental em ecossistemas terrestres tropicais brasileiros . In: ENCONTRO PESQUISA EM EDUCAÇÃO AMBIENTAL, 2., 2003, São Carlos. Atas...São Carlos: UFSCar, 2003. 1 CD-ROM.

PINHEIRO da SILVA, P. G.; CAVASSAN, O. A representatividade das ilustrações botânicas presentes nos livros didáticos de ciências no processo de ensino e aprendizagem . In: ENCONTRO PERSPECTIVAS DO ENSINO DE BIOLOGIA, 8., 2002, São Paulo. Anais...São Paulo: FEUSP, 2002. 1 CD-ROM.

PINHEIRO da SILVA, P. G. As ilustrações botânicas presentes nos livros didáticos de ciências: da representação impressa à realidade. 2004. 189 p. Dissertação (Mestrado em Educação para a Ciência) - Faculdade de Ciências da Universidade Estadual Paulista "Júlio de Mesquita Filho", Bauru, 2004.

SENICIATO, T.; CAVASSAN, O. A afetividade ao ambiente natural: o que nos revelam os livros didáticos. In: ENCONTRO "PERSPECTIVAS DO ENSINO DE BIOLOGIA", 8., 2002, São Paulo. Anais...São Paulo: FEUSP, 2002. 1 CD-ROM.

SENICIATO, T.; CAVASSAN, O. Aulas de campo em ambientes naturais e aprendizagem em ciências - um estudo com alunos do ensino fundamental. Ciência \& Educação. vol. 10, n. 1, p. 133-147, 2004.

TIERDERMANN, W. Conteúdos de química em livros didáticos de ciências. Ciência \& Educação. São Paulo, v.5 n.2, p.15-22, 1998.

VIGOTSKI, L.S. A construção do pensamento e da linguagem. São Paulo: Martins Fontes, 2001.

Data de recebimento: 15/03/2006

Data de aprovação: 08/06/2006 